\title{
Effect of the Physical Activities in Leisure Time and Commuting to Work on Mental Health
}

\author{
Masanori Oнta ${ }^{1}$, Tetsuya Mizoue ${ }^{2}$, Norio Mishima ${ }^{3}$ and Masaharu IredA ${ }^{4}$ \\ ${ }^{1}$ Department of Health Development, University of Occupational and Environmental Health, ${ }^{2}$ Department of \\ Preventive Medicine, Graduate School of Medical Sciences, Kyushu University, ${ }^{3}$ Ikemi Memorial Clinic of Mind- \\ Body Medicine and ${ }^{4}$ Kitakyushu Tsuyazaki Hospital, Japan
}

\begin{abstract}
Effect of the Physical Activities in Leisure Time and Commuting to Work on Mental Health: Masanori Онта, et al. Department of Health Development, University of Occupational and Environmental Health-Although some evidence suggests that exercise may improve mental health status, information regarding the intensity and duration of exercise is incomplete. The purpose of this study was to elucidate the association between physical activities in both leisure time and commuting to work and mental health. A questionnaire survey was conducted at three municipal offices in Japan. A total of 670 men and women completed the questionnaire. Mental health status was assessed by the 28 -item General Health Questionnaire (GHQ). Respondents were asked about weekly hours of leisure-time exercise for four levels of exercise, and the volume of exercise was assessed using a metabolic equivalent task index. Information about commuting to work on foot or by bicycle was also obtained. The mean GHQ scores were calculated according to physical activity levels using analysis of covariance with adjustment of potential confounders including job stress. In men, the GHQ score decreased steadily with increasing levels of leisure-time exercise, and an inverse association was evident even for mild intensity exercise. Moreover, the GHQ score decreased according to increasing duration of time on commuting to work by either walking or cycling in men, but not in women. These relations did not materially change after adjustment for potential confounding factors. In women, there was no significant association between any of the indices of physical activity. In conclusion, leisure-time exercise
\end{abstract}

Received May 31, 2006; Accepted Nov 13, 2006 Correspondence to: M. Ohta, Department of Health Development, Institute of Industrial Ecological Sciences, University of Occupational and Environmental Health, 1-1 Iseigaoka, Yahatanishi-ku, Kitakyushu 807-8555, Japan (e-mail: ohtamsn@med.uoeh-u.ac.jp) and walking or cycling during commuting to work may be associated with better mental health in men. (J Occup Health 2007; 49: 46-52)

Key word: GHQ, Physical activity, Commuting to work, Mental health

According to recent nation-wide surveys by Ministry of Health, Labour and Welfare, more than half of Japanese employees reported job-related distress such as high levels of worry, anxiety or stress at work, and historically the proportion has been over sixty percent in the last decade ${ }^{1)}$. As a result of the prolonged recession, employees in many Japanese companies have experienced organizational restructuring, including downsizing and outsourcing, which may be a new source of job stress ${ }^{2}$. In response to such a stressful working life, various measures have been taken or proposed which are directed not only for stress control at the worksite level, but also for personal lifestyles.

Because physical activity may have beneficial effects not only on physical health ${ }^{3-6)}$ but also on mental health ${ }^{7-12)}$, it is expected to be an important stress management technique for workers. Although Penedo et al. reviewed mental and physical health benefits associated with physical activity ${ }^{13)}$, it remains unclear what levels of intensity, frequency and duration of exercise are effective for stress control. Recently, Kull showed that even low levels of physical exercise in leisure time were related to good mental health in women ${ }^{14)}$, but this report focused only on the frequency of leisure-time exercise. For Japanese office workers, however, walking while commuting to work appears to be an important contribution to daily physical activity ${ }^{15)}$. Moreover, studies of physical activity and mental health to date ${ }^{8-12)}$ have not controlled for job stress, which may be associated with lower levels of leisure-time exercise ${ }^{16)}$ and thus may be a potential confounder of the association 
between exercise and mental health.

The purpose of the present study was to clarify the association between physical activities of leisure-time exercise and during commuting to work on mental health while considering job-related stress and other relevant confounding factors.

\section{Methods}

\section{Survey}

In 2001, a questionnaire survey was conducted as part of a worksite mental health promotion at three municipal offices in northern Kyushu, Japan. We distributed a study questionnaire to all full-time employees except those on long sick leave or maternity leave. A cover letter was also sent asking for the provision of their data for an epidemiologic study. Those who did not intend to participate in the study were asked to sign a rejection form. The completed questionnaire or the signed rejection form was returned to the health division of each office in a special envelope, which was then opened by a researcher. A total of 804 workers participated (97\% of eligible employees). After excluding 134 subjects who provided incomplete information for one or more of the items analyzed, 670 subjects remained for analysis. The present study was approved by the health committee of each office.

\section{Mental health status}

Mental health status was assessed using the 28-item General Health Questionnaire (GHQ), a self-administered screening instrument designed to detect psychological disorders. The GHQ was chosen, since it has been proven to be a simple and valid instrument for detecting psychologically disturbed persons in both clinical and non-clinical settings. According to Goldberg's method ${ }^{17)}$, four response options (1-2-3-4) were given scores of 0 $0-1-1$, and a total score was calculated by summing these scores for each person. Higher scores indicate higher psychological distress.

\section{Physical activity}

Self-rated intensity was used to assess physical activity in our study ${ }^{18)}$. Respondents were asked to state the weekly hours of leisure-time exercise engaged in for each of the four activities: strolling or walking; mild exercise, including golf and bowling; moderate intensity exercise, including tennis and volleyball; and strong intensity exercise, including football and basketball. Examples of the intensity referred to the table of classification of energy costs ${ }^{19}$. Total weekly hours of leisure-time exercise was calculated by summing the hours engaged in the four activities, and subjects were divided into three groups $(0,<3$, and $\geq 3 \mathrm{~h} / \mathrm{wk})$. Regarding the intensity of leisure-time exercise, mild intensity exercise was calculated as the sum of hours engaged in strolling or walking and mild exercises, and moderate or strong intensity exercise was calculated as the sum of hours engaged in moderate and strong exercises. Subjects were divided into three groups using cut-off levels of 0 and 3 hours per week for mild intensity exercise, and 0 and $1 \mathrm{~h}$ per week for moderate or strong intensity exercise, respectively. The metabolic equivalent task (MET) index was used to assess the volume of leisure-time exercise. By referring to a relevant article ${ }^{19,20)}$, we assigned MET values of 2, 4 and 6 to strolling or walking and mild exercise, moderate intensity exercise and strong intensity exercise, respectively. Then, we calculated weekly METhours for each activity by multiplying hours engaged in the activity and the corresponding MET and obtained total MET-hours by summing these values for each subject. One MET is the calorie needed per kilogram of body weight per hour of activity, divided by the calorie needed per kilogram per hour at rest and is equivalent to $3.5 \mathrm{~mL}$ of oxygen uptake per kilogram of body weight per minute, or to $1 \mathrm{kcal} / \mathrm{kg}$ of body weight per hour. The advantage of MET-hours is the ability to evaluate dose-response relationships across categories of mild, moderate and hard physical activity ${ }^{18)}$. Subjects were divided into three groups according to leisure-time exercise $(0,<12$, and $\geq 12 \mathrm{MET}-\mathrm{h} / \mathrm{wk}$ ).

We asked about whether subjects walked or used a bicycle to commute to work. If so, we further asked about daily minutes for each activity. Subjects were divided into three groups according to total minutes spent on these activities ( $<10,10-29$, and $\geq 30 \mathrm{~min})$.

\section{Confounding variables}

In the analysis of the relation between physical activity and mental health, confounding factors considered were age, marital status, occupational physical activity and job stress. Age was measured in number of years. Marital status contrasted being married with not being married. Occupational physical activity was divided into sedentary and active work according to job title. Clerical jobs were classified as sedentary work, and other types of work including child-care work, school lunch cooking, and technical jobs were grouped as physically active work. To assess job stress, we used the modified Brief Job Stress Questionnaire (BJSQ). The modified BJSQ includes questions about quantitative job overload (three items), qualitative job overload (three items), physical demands (one item), job control (three items), skill underutilization (one item), interpersonal conflict (three items), poor physical environment (one item), suitable job (one item), rewarding job (one item), and support from supervisors and co-workers (six items) $)^{21)}$. A score for job stress reflecting imbalance between workload and control and a score for support from supervisors and co-workers were calculated using an equation derived from a survey in Japanese companies ${ }^{22}$. A higher job stress score indicates 
greater stress, whereas a higher score for support from colleagues indicates lower stress. Since previous studies indicate that levels of physical activity and depressive status may differ between genders, men and women were studied separately ${ }^{10,12)}$.

\section{Statistical analysis}

We assessed statistical significance for continuous variables by the Mann-Whitney test and for categorical variables by Fisher's exact test in comparing the distribution of potential confounding variables according to physical activity. The GHQ score was transformed into a logarithmic scale before analysis because of its skewed distribution. Analysis of covariance was used to estimate the means of the GHQ score according to physical activity levels while adjusting for age, marital status, job stress, support from colleagues and occupational physical activity. The trend was tested by assigning 1, 2 and 3 to the lowest through highest levels of physical activity. A level of $p$ less than 0.05 was considered significant. All analyses were carried out using the SAS program, version 8.2 (SAS Institute Inc, Cary, NC).

\section{Results}

Table 1 summarizes gender differences on sample characteristics, job stress, physical exercise levels and GHQ score. All indices for leisure-time exercise levels were higher in men than in women, whereas physical activity during commuting to work did not differ between men and women. The GHQ score and job stress score were higher among women compared with men, but there was no significant gender difference in the score for support from colleagues. Men tended to be older, married and in sedentary work compared to women.

Table 2 shows the distribution of covariates by physical activity in leisure time or in commuting to work. In men, the mean age was the highest in those who spent more than $3 \mathrm{~h} / \mathrm{wk}$ on leisure-time exercise, and the job stress score decreased monotonically with increasing levels of leisure-time exercise. On the other hand, support from colleagues progressively improved with increasing levels of leisure-time exercise in women. In men and women, the proportion of sedentary work was greater for those who engaged in any physical activity on commuting to work than in those who did not.

Table 3 shows unadjusted and adjusted means of the GHQ score between physical activities at leisure and during commuting to work in men. The GHQ score decreased with increasing levels of total hours engaged and the volume of leisure-time exercise. The inverse association was similarly observed both for mild and moderate or strong intensity exercise, although statistical significance was not attained for moderate or strong exercise. Moreover, the GHQ score decreased with increasing duration of commuting time to and from work either on foot or by bicycle. These relations did not materially change after adjustment for potential confounding factors. In women, an inverse association with the GHQ score was not observed for any of the indices of physical activity (Table 4).

\section{Discussion}

A healthy lifestyle, such as eating breakfast regularly, adequate sleep hours, exercising and not smoking ${ }^{23)}$, as well as active coping, is associated with lower psychological distress among workers. Although a number of studies have reported the favorable effect of exercise on mental status, detailed information regarding the volume (e.g., intensity, frequency and duration) of physical activity is still being debated. Engaging in regular aerobic physical activity such as brisk walking (at least $30 \mathrm{~min}$ per day, most days of the week) is generally recommended for prevention of lifestyle-related diseases including hypertension ${ }^{24}$. The present study shows that even a mild intensity exercise or small volume of exercise (less than $12 \mathrm{MET}$-h/wk) was associated with a lower GHQ score in men, suggesting that habitual leisure exercise per se contributed directly to a better mental health status, irrespective of the intensity or volume of exercise.

Few studies have focused on the relation between mental health and commuting to work. The prospective data of the Osaka Health Survey showed that the duration of the walk to work was associated with a decreased risk for incident hypertension, moreover even persons who drive to work or use public transportation may benefit form parking or leaving their transportation more than 20 min walk from the office ${ }^{15}$. This study, however, did not focus on the issue of mental health. Our study indicates that $30 \mathrm{~min}$ or longer round-trip commuting, either on foot or by bicycle, had a significant effect on mental health status.

The beneficial effect of physical activity on mental health was evident only in men, but not in women. However, Kull showed that even a low level of physical activity was positively related to mental health in women $^{14)}$. The reason for this inconsistency is unknown, but the difference in the subject age range from 18 to 45 yr in Kull's study and from 18 to 60 in the present study or ethnic composition may partly account for the discrepancy. Lindquist et al. showed that job stress was higher in men than in women, and that men exercised more than women ${ }^{25}$. On the other hand, Iwata et al. reported that mean scores on the GHQ were higher in women than in men in Japan ${ }^{26)}$. The present study showed that job stress and GHQ score were higher in women than in men, and the mean of MET-h/wk was lower in women than in men. Middle-aged women, in particular married women, are in general highly involved in child 
Table 1. Characteristics of subjects

\begin{tabular}{|c|c|c|c|c|c|c|}
\hline \multirow[b]{2}{*}{ Age in yr, mean (SD) } & & \multicolumn{2}{|c|}{ Men $(n=427)$} & \multicolumn{2}{|c|}{ Women $(n=243)$} & \multirow{2}{*}{$\frac{p}{<0.0001^{*}}$} \\
\hline & & 41.8 & $(10.8)$ & 38.0 & $(10.9)$ & \\
\hline \multirow[t]{2}{*}{ Marital status, $\%$} & Married & 73.5 & & 53.5 & & $<0.0001^{\dagger}$ \\
\hline & Non-married & 26.5 & & 46.5 & & \\
\hline \multirow[t]{2}{*}{ Occupational physical activity, $\%$} & Sedentary work & 78.0 & & 45.3 & & $<0.0001^{\dagger}$ \\
\hline & Active work & 22.0 & & 54.7 & & \\
\hline \multicolumn{2}{|l|}{ Job stress score, mean (SD) } & 98.4 & $(25.5)$ & 100.9 & $(6.6)$ & $0.0009^{*}$ \\
\hline \multicolumn{2}{|c|}{ Score for support from colleagues, mean (SD) } & 96.6 & $(35.3)$ & 97.3 & $(31.0)$ & $0.44 *$ \\
\hline \multicolumn{2}{|c|}{ Leisure-time exercise, hours/week, mean (SD) } & 3.1 & $(3.7)$ & 1.7 & $(2.9)$ & $<0.0001^{*}$ \\
\hline \multicolumn{2}{|c|}{ Leisure-time exercise, MET-hours/week, mean (SD) } & 8.5 & $(11.0)$ & 4.1 & $(7.0)$ & $<0.0001^{*}$ \\
\hline \multicolumn{2}{|c|}{ Walking/cycling in commuting to work, min/day, mean (SD) } & 7.7 & $(14.0)$ & 7.6 & $(12.7)$ & $0.57 *$ \\
\hline \multicolumn{2}{|l|}{ GHQ sore, mean (SD) } & 5.4 & $(5.4)$ & 6.7 & $(5.4)$ & $0.0002^{*}$ \\
\hline
\end{tabular}

*Mann-Whitney’s U test. †Fisher's exact test.

Table 2. Occupational and personal factors in relation to leisure-time physical activity, and activity in commuting to work for men and women

\begin{tabular}{|c|c|c|c|c|c|c|c|}
\hline Variables & & $\mathrm{n}$ & $\begin{array}{l}\text { Age in yr, } \\
\text { mean (SD) }\end{array}$ & $\begin{array}{r}\text { Marital } \\
\text { status, \% } \\
\text { married }\end{array}$ & $\begin{array}{c}\text { Occupational } \\
\text { physical activity, } \\
\% \text { sedentary work }\end{array}$ & $\begin{array}{l}\text { Job stress } \\
\text { score, mean } \\
\quad(\mathrm{SD})^{\text {Il }}\end{array}$ & $\begin{array}{c}\text { Score for support } \\
\text { from colleagues, } \\
\text { mean }(\mathrm{SD})^{\mathrm{I}}\end{array}$ \\
\hline \multicolumn{8}{|l|}{$\operatorname{Men}(n=427)$} \\
\hline \multirow{4}{*}{$\begin{array}{l}\text { Leisure-time } \\
\text { exercise (h/wk) }\end{array}$} & no & 125 & $41.2(10.4)$ & 68.8 & 78.4 & 101.4 (31.0) & $101.7(39.1)$ \\
\hline & $<3$ & 109 & $39.7(10.3)$ & 70.6 & 78.1 & 100.9 & $96.7(35.4)$ \\
\hline & $\geq 3$ & 193 & 43.4 (11.1) & 78.2 & 77.2 & $95.0 \quad(21.4)$ & $93.3(32.5)$ \\
\hline & & & $p^{*}=0.01$ & $p^{\dagger}=0.12$ & $p^{\dagger}=0.95$ & $p^{*}=0.048$ & $p^{*}=0.12$ \\
\hline \multirow{4}{*}{$\begin{array}{l}\text { Leisure-time } \\
\text { exercise } \\
(\mathrm{MET}-\mathrm{h} / \mathrm{wk})\end{array}$} & no & 125 & $41.2(10.4)$ & 68.8 & 78.4 & 101.4 & $101.7(39.1)$ \\
\hline & $<12$ & 181 & $41.9(10.2)$ & 74.6 & 76.2 & 100.2 & $95.1(32.1)$ \\
\hline & $\geq 12$ & 121 & $42.3(12.1)$ & 76.9 & 80.2 & $92.6(21.1)$ & $93.6(35.6)$ \\
\hline & & & $p^{*}=0.74$ & $p^{\dagger}=0.33$ & $p^{\dagger}=0.72$ & $p^{*}=0.01$ & $p^{*}=0.15$ \\
\hline \multirow{4}{*}{$\begin{array}{l}\text { Walking/cycling in } \\
\text { commuting to } \\
\text { work }(\mathrm{min} / \mathrm{d})\end{array}$} & no & 298 & $41.0(10.9)$ & 51.5 & 74.8 & $98.0 \quad(25.2)$ & $96.0(34.9)$ \\
\hline & $<30$ & 88 & $43.7 \quad(9.7)$ & 77.3 & 89.8 & 102.5 & $97.0(36.6)$ \\
\hline & $\geq 30$ & 41 & 43.5 (11.7) & 63.4 & 75.6 & $92.7 \quad(24.4)$ & $100.0(36.2)$ \\
\hline & & & $p^{*}=0.06$ & $p^{\dagger}=0.26$ & $p^{\dagger}=0.01$ & $p^{*}=0.11$ & $p^{*}=0.79$ \\
\hline \multicolumn{8}{|l|}{ Women $(n=243)$} \\
\hline \multirow{4}{*}{$\begin{array}{l}\text { Leisure-time } \\
\text { exercise (h/wk) }\end{array}$} & no & 119 & $38.3(10.5)$ & 53.8 & 41.2 & $101.6 \quad(6.4)$ & $102.5(32.9)$ \\
\hline & $<3$ & 67 & $36.6(10.6)$ & 61.2 & 50.8 & 100.5 & $94.7(29.6)$ \\
\hline & $\geq 3$ & 57 & 38.9 (12.2) & 43.9 & 47.4 & $99.7 \quad(6.6)$ & $89.4(26.7)$ \\
\hline & & & $p^{*}=0.44$ & $p^{\dagger}=0.16$ & $p^{\dagger}=0.43$ & $p^{*}=0.17$ & $p^{*}=0.02$ \\
\hline \multirow{4}{*}{$\begin{array}{l}\text { Leisure-time } \\
\text { exercise } \\
(\mathrm{MET}-\mathrm{h} / \mathrm{wk})\end{array}$} & no & 119 & $38.3(10.5)$ & 53.8 & 41.2 & $101.6 \quad(6.4)$ & $102.5(32.9)$ \\
\hline & $<12$ & 96 & 37.4 (11.4) & 52.1 & 53.1 & $100.4 \quad(7.2)$ & $92.8(28.7)$ \\
\hline & $\geq 12$ & 28 & $38.6(11.5)$ & 57.1 & 35.7 & $99.1 \quad(5.2)$ & $90.3(27.2)$ \\
\hline & & & $p^{*}=0.79$ & $\mathrm{p}^{\dagger}=0.89$ & $p^{\dagger}=0.12$ & $p^{*}=0.14$ & $p^{*}=0.03$ \\
\hline \multirow{4}{*}{$\begin{array}{l}\text { Walking/cycling in } \\
\text { commuting to } \\
\text { work (min/d) }\end{array}$} & no & 167 & $38.2(10.6)$ & 55.1 & 38.9 & $100.6 \quad(5.9)$ & 98.7 (29.4) \\
\hline & $<30$ & 51 & 35.7 (11.0) & 41.2 & 60.8 & 102.5 & $97.4(36.5)$ \\
\hline & $\geq 30$ & 25 & $41.3(12.5)$ & 68.0 & 56.0 & $99.2 \quad(6.4)$ & $87.4(29.2)$ \\
\hline & & & $p^{*}=0.10$ & $p^{\dagger}=0.07$ & $p^{\dagger}=0.01$ & $p^{*}=0.09$ & $p^{*}=0.24$ \\
\hline
\end{tabular}

Values in the table are mean (SD) or \% $*$ ANOVA, ${ }^{\dagger}$ Fisher’s exact test, ${ }^{\llbracket I H i g h e r ~ v a l u e ~ i n d i c a t e s ~ g r e a t e r ~ j o b ~ s t r e s s ~ o r ~ l o w e r ~ s u p p o r t ~}$ from colleagues. 
Table 3. Relation between GHQ score and activity in leisure time, and commuting to work for men

\begin{tabular}{|c|c|c|c|c|c|c|}
\hline & Variables & $\mathrm{n}$ & $\begin{array}{c}\text { Unadjusted mean } \\
(95 \% \mathrm{CI})\end{array}$ & $p^{*}$ & $\begin{array}{c}\text { Adjusted mean** } \\
(95 \% \mathrm{CI})\end{array}$ & $p^{*}$ \\
\hline \multicolumn{7}{|l|}{ Leisure-time exercise (h/wk) } \\
\hline \multirow[t]{3}{*}{ Any intensity } & no & 125 & $4.73(3.89,5.71)$ & reference & $4.11(3.29,5.09)$ & reference \\
\hline & $<3$ & 109 & $4.02 \quad(3.27,4.92)$ & 0.41 & $3.53(2.77,4.46)$ & 0.26 \\
\hline & $\geq 3$ & 193 & $\begin{array}{l}2.56 \quad(2.15,3.03) \\
p \text { for trend }<0.0001\end{array}$ & $<0.0001$ & $\begin{array}{l}2.62(2.11,3.21) \\
p \text { for trend }=0.0003\end{array}$ & 0.0003 \\
\hline \multirow[t]{3}{*}{ Mild intensity } & no & 188 & $4.16(3.51,4.90)$ & reference & $3.49(2.71,4.44)$ & reference \\
\hline & $<3$ & 107 & $3.86 \quad(3.17,4.68)$ & 0.81 & $3.20(2.37,4.24)$ & 0.51 \\
\hline & $\geq 3$ & 132 & $\begin{array}{l}2.40(1.94,2.94) \\
p \text { for trend }<0.0001\end{array}$ & $<0.0001$ & $\begin{array}{l}2.23(1.64,2.95) \\
p^{\mathbb{I}} \text { for trend }=0.001\end{array}$ & 0.0009 \\
\hline \multirow[t]{4}{*}{ Moderate or strong intensity } & no & 322 & $3.65 \quad(3.22,4.14)$ & reference & $3.41(2.86,4.04)$ & reference \\
\hline & $\leq 1$ & 20 & $2.57 \quad(1.38,4.35)$ & 0.36 & $2.75(1.59,4.42)$ & 0.39 \\
\hline & $>1$ & 85 & $3.04 \quad(2.36,3.87)$ & 0.36 & $2.69(1.98,3.57)$ & 0.09 \\
\hline & & & $p$ for trend $=0.15$ & & $p^{\mathbb{I}}$ for trend $=0.055$ & \\
\hline \multicolumn{7}{|l|}{ Leisure-time exercise (MET-h/wk) } \\
\hline & no & 125 & $4.73(3.89,5.71)$ & reference & $4.08(3.26,5.06)$ & reference \\
\hline & $<12$ & 181 & $3.28 \quad(2.77,3.86)$ & 0.009 & $2.98(2.41,3.65)$ & 0.012 \\
\hline & $\geq 12$ & 121 & $\begin{array}{l}2.69(2.15,3.32) \\
p \text { for trend }=0.0001\end{array}$ & 0.0002 & $\begin{array}{l}2.81(2.18,3.55) \\
p \text { for trend }=0.006\end{array}$ & 0.007 \\
\hline \multicolumn{7}{|c|}{ Walking/cycling in commuting to work (min/d) } \\
\hline & no & 298 & $3.75 \quad(3.20,4.38)$ & reference & $3.82(3.29,4.43)$ & reference \\
\hline & $<30$ & 88 & $3.49 \quad(2.95,4.09)$ & 1.00 & $3.81(2.96,4.83)$ & 0.97 \\
\hline & $\geq 30$ & 41 & $\begin{array}{l}2.22(1.34,3.44) \\
p \text { for trend }=0.056\end{array}$ & 0.03 & $\begin{array}{l}2.62(1.80,3.68) \\
p \text { for trend }=0.089\end{array}$ & 0.04 \\
\hline
\end{tabular}

GHQ score was expressed as geometric mean (95\% conference intervals). * $p$ for differences from reference. **Adjusted for age, marital status, occupational physical activity, job stress and support from colleagues by using analysis of covariance. IAs to the analysis for mild intensity of leisure-time exercise, the variable representing moderate or strong intensity of leisure-time exercise was added in a multivariate model in stead of the variable representing overall leisure-time exercise, and vice versa for moderate or strong intensity of leisure-time exercise.

care and/or housework, which should affect both time available for leisure-time exercise and mental health status. Therefore, the lack of consideration about such daily life activities in the present study may explain the absence of significant association between leisure-time excise and mental health in women.

Our study has several limitations. First, the crosssectional design limits causal inference. Whether exercise can contribute to good mental health needs to be examined in controlled studies. Second, physical activity levels were assessed based on a self-administered questionnaire, and neither physical fitness measures nor evaluation of physical activity using accelerometry-based physical activity monitors were available. However, self-reports of physical activity are fairly accurate ${ }^{27,28}$. Third, cutpoint bias may occur when cut-off levels are determined to maximize the desired effect (e.g., statistical significance, magnitude of effect, or data trends) or are fit to the population-specific data distribution (e.g., sample tertile cut-point $)^{18)}$. However, we confirmed that the results did not change materially with varying cut-off points from 9 to 12 MET-h per week (data not shown). Fourth, although we considered occupational physical activity levels and work-related stress in the analysis, we did not include other potential confounders including office organization and daily activities in the office. Moreover, we did not obtain information about commuting times of all subjects, so the present finding may reflect an even lower stress score among those who walk or use a bicycle to commute compared to those who do not. Fifth, since all participants were full-time employees of three municipal offices in Northern Kyushu, the present results need to be confirmed in other occupations or industrial sectors. Finally, since the present study assessed general mental health status rather than a clinically depressive state, our findings should not be directly linked to curative measures for depression.

In conclusion, the present study adds to evidence that leisure-time exercise and walking or cycling during commuting to work are each associated with better mental 
Table 4. Relation between GHQ score and activity in leisure time, and commuting to work for women

\begin{tabular}{|c|c|c|c|c|c|c|}
\hline & Variables & $\mathrm{n}$ & $\begin{array}{l}\text { Unadjusted mean } \\
\qquad(95 \% \mathrm{CI})\end{array}$ & $p^{*}$ & $\begin{array}{l}\text { Adjusted mean } * * \\
\qquad(95 \% \mathrm{CI})\end{array}$ & $p^{*}$ \\
\hline \multicolumn{7}{|l|}{ Leisure-time exercise (h/wk) } \\
\hline \multirow[t]{4}{*}{ Any intensity } & no & 119 & $4.71 \quad(3.88,5.70)$ & reference & $3.82(3.29,4.43)$ & reference \\
\hline & $<3$ & 67 & $4.69 \quad(3.70,5.90)$ & 0.99 & $3.81(2.96,4.83)$ & 0.46 \\
\hline & $\geq 3$ & 57 & $4.94 \quad(3.72,6.48)$ & 0.95 & $2.62(1.80,3.68)$ & 0.10 \\
\hline & & & $p$ for trend $=0.81$ & & $p$ for trend $=0.10$ & \\
\hline \multirow[t]{4}{*}{ Mild intensity } & no & 139 & $4.59 \quad(3.83,5.47)$ & reference & $4.49(3.33,5.95)$ & reference \\
\hline & $<3$ & 61 & $5.27 \quad(4.20,6.57)$ & 0.60 & $5.35(3.74,7.49)$ & 0.23 \\
\hline & $\geq 3$ & 43 & $4.64 \quad(3.31,6.36)$ & 1.00 & $5.44(3.69,7.84)$ & 0.26 \\
\hline & & & $p$ for trend $=0.75$ & & 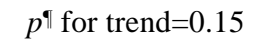 & \\
\hline \multirow[t]{4}{*}{ Moderate or strong intensity } & no & 213 & $4.86 \quad(4.25,5.56)$ & reference & $5.17(4.36,6.10)$ & reference \\
\hline & $\leq 1$ & 10 & $3.67 \quad(1.65,7.23)$ & 0.65 & $4.50(2.29,8.19)$ & 0.65 \\
\hline & $>1$ & 20 & $4.32 \quad(2.40,7.32)$ & 0.86 & $5.61(3.63,8.46)$ & 0.71 \\
\hline & & & $p$ for trend $=0.48$ & & 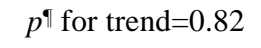 & \\
\hline \multicolumn{7}{|c|}{ Leisure-time exercise (MET-h/wk) } \\
\hline & no & 119 & $4.72 \quad(3.89,5.70)$ & reference & $4.56(3.70,5.56)$ & reference \\
\hline & $<12$ & 96 & $5.01 \quad(4.14,6.03)$ & 0.89 & $5.52(4.45,6.78)$ & 0.14 \\
\hline & $\geq 12$ & 28 & $4.15 \quad(2.61,6.34)$ & 0.80 & $5.08(3.50,7.20)$ & 0.59 \\
\hline & & & $p$ for trend $=0.80$ & & $p$ for trend $=0.28$ & \\
\hline \multicolumn{7}{|c|}{ Walking/cycling in commuting to work (min/d) } \\
\hline & no & 167 & $4.87 \quad(4.11,5.76)$ & reference & $4.79(4.12,5.55)$ & reference \\
\hline & $<30$ & 51 & $4.65 \quad(3.68,5.81)$ & 0.47 & $5.15(3.94,6.66)$ & 0.63 \\
\hline & $\geq 30$ & 25 & $4.58 \quad(2.82,7.17)$ & 1.00 & $5.35(3.66,7.66)$ & 0.59 \\
\hline & & & $p$ for trend $=0.62$ & & $p$ for trend $=0.58$ & \\
\hline
\end{tabular}

GHQ score was expressed as geometric mean (95\% conference intervals). * $p$ for differences from reference, **Adjusted for age, marital status, occupational physical activity, job stress and support from colleagues by using analysis of covariance. $\mathbb{T}$ As to the analysis for mild intensity of leisure-time exercise, the variable representing moderate or strong intensity of leisure-time exercise was added in a multivariate model in stead of the variable representing overall leisure-time exercise, and vice versa for moderate or strong intensity of leisure-time exercise.

health in men. Controlled studies are needed to confirm causality concerning physical activity and mental health.

Acknowledgments: We are grateful to officers of Administration Divisions and the occupational health nurses. This work was supported in part by a Grant-inAid for a UOEH Grant for Advanced Research.

\section{References}

1) Ministry of Labour, Japan. A survey on health status of employees in 2002. Tokyo: Ministry of Labour, 2003 (in Japanese).

2) Kawakami $\mathrm{N}$ and Haratani T: Epidemiology of job stress and health in Japan: review of current evidence and future direction. Ind Health 37, 174-186 (1999)

3) Ekelund LG, Haskell WL, Johnson JL, Whaley FS, Criqui $\mathrm{MH}$ and Sheps DS: Physical fitness as a predictor of cardiovascular mortality in asymptomatic North American men. The lipid research clinics mortality follow-up study. N Engl J Med 319, 13791384 (1988)
4) Paffenbarger RS Jr, Hyde RT, Wing AL, Lee IM, Jung DL and Kampert JB: The association of changes in physical activity level and other lifestyle characteristics with mortality among men. N Engl J Med 328, 538545 (1993)

5) Blair SN, Kohl HW 3rd, Barlow CE, Paffenbarger RS Jr, Gibbons LW and Macera CA: Changes in physical fitness and all-cause mortality. A prospective study of healthy and unhealthy men. JAMA 273, 1093-1098 (1995)

6) Friedenreich $\mathrm{CM}$ and Orenstein MR: Physical activity and cancer prevention: etiologic evidence and biological mechanisms. J Nutr 132 (Suppl 11), 3456S3464S (2002)

7) Paluska SA and Schwenk TL: Physical activity and mental health: current concepts. Sports Med 29, $167-$ 180 (2000)

8) Ross CE and Hayes D: Exercise and psychologic wellbeing in the community. Am J Epidemiol 127, 762771 (1988)

9) Stephens T: Physical activity and mental health in the 
United States and Canada: evidence from four population surveys. Prev Med 17, 35-47 (1988)

10) Camacho TC, Roberts RE, Lazarus NB, Kaplan GA and Cohen RD: Physical activity and depression: evidence from the Alameda County Study. Am J Epidemiol 134, 220-231 (1991)

11) Paffenbarger RS Jr, Lee IM and Leung R: Physical activity and personal characteristics associated with depression and suicide in American college men. Acta Psychiatr Scand Suppl 377, 16-22 (1994)

12) Farmer ME, Locke BZ, Moscicki EK, Dannenberg AL, Larson DB and Radloff LS: Physical activity and depressive symptoms: the NHANES I Epidemiologic Follow-up Study. Am J Epidemiol 128, 1340-1351 (1988)

13) Pendo FJ and Dahn JR: Exercise and well-being: a review of mental and physical health benefits associated with physical activity. Curr Opin Psychiatry 18, 189-193 (2005)

14) Kull M: The relationships between physical activity, health status and psychological well-being of fertilityaged women. Scand J Med Sci Sports 12, 241-247 (2002)

15) Hayashi T, Tsumura K, Suematsu C, Okada K, Fujii $S$ and Endo G: Walking to work and the risk for hypertension in men: the Osaka Health Survey. Ann Intern Med 131, 21-26 (1999)

16) Kouvonen A, Kivimaki M, Elovainio M, Virtanen M, Linna A and Vahtera J: Job strain and leisure-time physical activity in female and male public sector employees. Prev Med 41, 532-539 (2005)

17) Goldberg D. Manual of the general health questionnaire. NBerkshire, UK: NFER-Nelson, 1978: 8-13.

18) Lamonte MJ and Ainsworth BE: Quantifying energy expenditure and physical activity in the context of dose response. Med Sci Sports Exerc 33 (Suppl 6), S370 S378 (2001)

19) Ainsworth BE, Haskell WL, Leon AS, Jacobs DR Jr, Montoye HJ, Sallis JF and Paffenbarger RS Jr: Compendium of physical activities: classification of energy costs of human physical activities. Med Sci Sports Exerc 25, 71-80 (1993)

20) Miyaki K, Sutani S, Kikuchi H, Takei I, Murata M, Watanabe $\mathrm{K}$ and Omae $\mathrm{K}$ : Increased risk of obesity resulting from the interaction between high energy intake and the Trp64Arg polymorphism of the beta3adrenergic receptor gene in healthy Japanese men. J Epidemiol 15, 203-210 (2005)

21. Kawakami N, Takao S, Kobayashi Y and Tsutsumi A: Effects of web-based supervisor training on job stressors and psychological distress among workers: a workplace-based randomized controlled trial. J Occup Health 48, 28-34 (2006)

22) Ministry of Labour, Japan. A research report relating to stress in the workplace and its impact on workers' health in 1999. Tokyo: Ministry of Labour, 2000 (in Japanese).

23) Maruyama $\mathrm{S}$ and Morimoto K: Effects of long workhours on life-style and quality of life among intermediate Japanese managers. Scand J Work Environ Health 22, 353-359 (1996)

24) Chobanian AV, Bakris GL, Black HR, Cushman WC, Green LA, Izzo JL Jr, Jones DW, Materson BJ, Oparil S, Wright JT Jr and Roccella EJ: National Heart, Lung, and Blood Institute Joint National Committee on Prevention, Detection, Evaluation, and Treatment of High Blood Pressure; National High Blood Pressure Education Program Coordinating Committee: The 7th Report of the Joint National Committee on Prevention, Detection, Evaluation, and Treatment of High Blood Pressure: the JNC 7 Report. JAMA 289, 2560-2572 (2003)

25) Lindquist TL, Beilin LJ and Knuiman MW: Influence of lifestyle, coping, and job stress on blood pressure in men and women. Hypertension 29, 1-7 (1997)

26) Iwata N, Kawakami N, Haratani T, Murata K and Araki S: Job stressor-mental health associations in a sample of Japanese working adults: artifacts of positive and negative questions? Ind Health 37, 263-270 (1999)

27) Blair SN, Dowda M, Pate RR, Kronenfeld J, Howe HG Jr, Parker G and Blair A: Reliability of long-term recall of participation in physical activity by middleaged men and women. Am J Epidemiol 133, 266-275 (1991)

28) Taylor CB, Coffey T, Berra K, Iaffaldano R, Casey K and Haskell WL: Seven-day activity and self-report compared to a direct measure of physical activity. Am J Epidemiol 120, 818-824 (1984) 